OPEN ACCESS

Edited by: Afshin Ostovar Tehran University of Medical

Sciences, Iran

Reviewed by:

Bo Jia,

Shanghai General Hospital, China Sarah Damanti,

University of Milan, Italy

*Correspondence:

Bo Yu

ybshengzhongyi@126.com

†These authors have contributed equally to this work

Specialty section:

This article was submitted to Geriatric Medicine,

a section of the journal

Frontiers in Medicine

Received: 02 January 2021

Accepted: 25 March 2021

Published: 16 April 2021

Citation:

Li D, Lin H, Zhang M, Meng J, Hu L and Yu B (2021) Urine Cadmium as a

Risk Factor for Osteoporosis and Osteopenia: A Meta-Analysis.

Front. Med. 8:648902.

doi: 10.3389/fmed.2021.648902

\section{Urine Cadmium as a Risk Factor for Osteoporosis and Osteopenia: A Meta-Analysis}

\author{
Dong $\mathrm{Li}^{1+}$, HaoJie Lin ${ }^{2 \dagger}$, Min Zhang ${ }^{3+}$, Jing Meng ${ }^{1}$, LiYou Hu${ }^{1}$ and Bo $\mathrm{Yu}^{4 *}$ \\ ${ }^{1}$ The Chinese Medicine College, Shandong University of Traditional Chinese Medicine, Jinan, China, ${ }^{2}$ Jinan Blood Supply \\ and Security Center, Jinan, China, ${ }^{3}$ Department of Nursing, Affiliated Hospital of Shandong University of Traditional Chinese \\ Medicine, Jinan, China, ${ }^{4}$ Department of Orthopedics, Affiliated Hospital of Shandong University of Traditional Chinese \\ Medicine, Jinan, China
}

Background: As society ages, the incidence of osteoporosis increases. In several studies, cadmium (Cd) is thought to be related to osteoporosis. However, there are conflicting reports about the relationship between $\mathrm{Cd}$ and the risk of osteoporosis and osteopenia. Therefore, the purpose of this meta-analysis was to explore the relationship between $\mathrm{Cd}$ and osteoporosis and osteopenia.

Methods: Through a review of the literature, articles published in PubMed as of December 2020 were identified and the references of related publications and reviews were reviewed. Ultimately, 17 eligible articles were selected to determine the relationship between blood and urine Cd concentrations for the risk of osteoporosis or osteopenia. In this study, we performed a classification analysis, heterogeneity test, subgroup analysis, and evaluated publication bias.

Results: A total of 17 studies were included, including seven on blood $\mathrm{Cd}$ and 10 on urine $\mathrm{Cd}$. By combining the odds ratio (OR) and 95\% confidence interval (Cl) for the lowest and highest categories, the odds ratio of blood Cd concentration that increased the risk of osteoporosis or osteopenia was OR 1.21 (95\% Cl: 0.84-1.58) and that of urine $\mathrm{Cd}$ concentration that increased the risk of osteoporosis or osteopenia was OR 1.80 (95\% Cl: 1.42-2.18), and the results of the subgroup analysis were also consistent.

Conclusions: Our research indicates that while urine cadmium (Cd) concentration may be related to increased risk of osteoporosis and osteopenia, blood $\mathrm{Cd}$ concentration may not. Therefore, compared to blood Cd concentration, urine $\mathrm{Cd}$ concentration may be more reliable as a risk factor for osteoporosis and osteopenia. This result should be interpreted with caution. Currently. research on the relationship between $\mathrm{Cd}$ concentration and osteoporosis and osteopenia is limited, thus, further large, high-quality prospective studies are required to elucidate the relationship between $\mathrm{Cd}$ concentration and osteoporosis and osteopenia.

Keywords: cadmium, osteoporosis, osteopenia, meta-analysis, risk factor 


\section{INTRODUCTION}

Osteoporosis is a systemic bone disease characterized by decreased bone mineral density, bone microstructure destruction, and increased risk of fragility fractures. Due to the high morbidity and mortality of diseases such as osteoporosis, fragility fractures, and other diseases, it has become a public health problem that needs to be solved urgently $(1,2)$. Some metals such as zinc, iron, and copper are closely related to human bones and are necessary to maintain normal physiological functions. However, heavy metals have been reported as risk factors for degenerative diseases such as osteoporosis and associated fractures $(3,4)$.

Cadmium $(\mathrm{Cd})$ is a toxic non-essential transition metal. With the acceleration of global industrialization, $\mathrm{Cd}$ and its inorganic compounds are widely used in the manufacturing process of electroplating, batteries, pigments, plastics, and alloys. A large amount of $\mathrm{Cd}$ will enter the soil and, ultimately, the human body through contaminated food and water (5). $\mathrm{Cd}$ accumulates in plants and animals, and its half-life is $\sim 10$-30 years. Epidemiological data indicate that occupational and environmental $\mathrm{Cd}$ exposure may be related to various types of cancer, and Cd may be a risk factor for osteoporosis (6). A number of animal studies have shown that $\mathrm{Cd}$ can directly affect bone density by stimulating osteoclast differentiation and activity (7) and can indirectly affect bone health by affecting other organ systems, such as the gastrointestinal tract, thyroid, and especially, the kidneys $(8,9)$. However, the results of investigations on the relationship among human
Cd intake, body Cd concentration, and osteoporosis are not consistent. Songprasert et al. reported that excessive exposure and intake of $\mathrm{Cd}$ will cause bone density reduction and osteoporosis (10). Li X et al. also reached the same conclusion (11). However, Trzcinka-Ochocka suggested that Cd has no correlation with osteoporosis and bone density (12). Therefore, clarifying the relationship between $\mathrm{Cd}$ concentration and osteoporosis or osteopenia is helpful in the formulation of clinical policies and guidelines. However, there is currently no relevant meta-analysis to explain the relationship between blood and urine Cd concentrations and the risk of osteoporosis and osteopenia.

Therefore, the purpose of this meta-analysis was to explore the relationship between blood and urine Cd concentrations and the risk of osteoporosis or osteopenia.

\section{METHODS}

Ethical approval and written informed consent from patients were not necessary because our study was based on summaries and analyses of results of existing studies.

\section{Search Strategy and Data Sources}

Free keywords were used to search for articles published in PubMed till December 2020. The search words used were "cadmium," "osteoporosis," "osteopenia," and "bone density." In addition, in order to obtain further relevant literature, we manually searched the references for related articles.

\section{Records identified through database searching $(n=366)$}

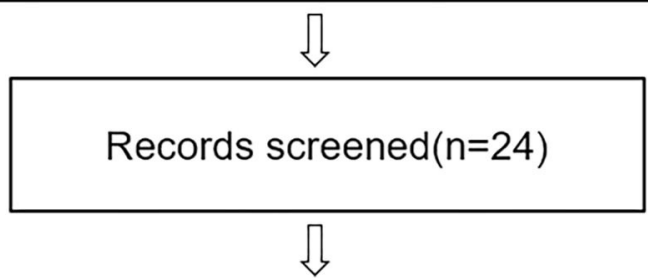

Full-text articles assessed for eligibility $(n=17)$

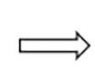

Excluding articles:

Without exact data $(n=3)$;

Non-op $(n=2)$; others $(n=2)$

\begin{tabular}{|c|}
\hline Excluding articles: \\
Without exact data( $(n=3) ;$ \\
Non-op $(n=2) ;$ \\
others $(n=2)$
\end{tabular}

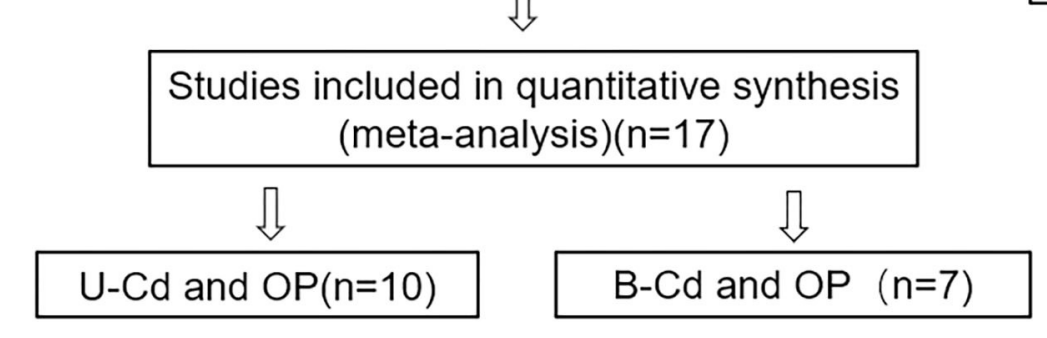

FIGURE 1 | Flowchart of the studies selection. 
TABLE 1 | Summary characteristics of studies and participants.

\begin{tabular}{|c|c|c|c|c|c|c|c|}
\hline References & Measured & Study type & Age (years) & Male-female ratio & Number & Country & BMD measured \\
\hline Lim et al. (24) & $\mathrm{B}-\mathrm{Cd}$ & Cross-sectional & $>18$ & 1,229/1,200 & 2,429 & Korea & \\
\hline Burm et al. (23) & $\mathrm{B}-\mathrm{Cd}$ & Cross-sectional & 40.3 & $1,275 /-$ & 1,275 & Korea & Dual-energy X-ray \\
\hline Choi and Han (22) & $\mathrm{B}-\mathrm{Cd}$ & Cross-sectional & 58.81 & $1,089 /-$ & 1,089 & Korea & Dual-energy X-ray \\
\hline Chen et al. (21) & $\mathrm{B}-\mathrm{Cd}$ & Cross-sectional & $\begin{array}{l}\text { Women Control area } 51.9 \\
\text { Women Polluted area } 58.7 \\
\text { Men Control area } 57.2 \\
\text { Men Polluted area } 64.2\end{array}$ & $119 / 202$ & 321 & China & Dual energy X-ray \\
\hline Pollack et al. (20) & $\mathrm{B}-\mathrm{Cd}$ & Cross-sectional & 27.4 & $-/ 248$ & 248 & America & Dual energy X-ray \\
\hline Cho et al. (19) & $\mathrm{B}-\mathrm{Cd}$ & Cross-sectional & $62.1 \pm 8.2$ & $-/ 481$ & 481 & Korea & Dual energy X-ray \\
\hline Alfvén et al. (18) & $\mathrm{B}-\mathrm{Cd}$ & Cross-sectional & $\begin{array}{l}\text { Men } 54 \\
\text { Women } 52\end{array}$ & $479 / 542$ & 1,021 & Sweden & Dual energy X-ray \\
\hline Lv et al. (32) & U-Cd & Cross-sectional & $\begin{array}{l}\text { Non-Cd-polluted area } 56.9 \\
\text { Cd-polluted area } 55.8\end{array}$ & $511 / 605$ & 1,116 & China & Dual energy X-ray \\
\hline Van Larebekea et al. (34) & U-Cd & Cross-sectional & $50-65$ & $-/ 808$ & 808 & Belgium & Dual energy X-ray \\
\hline Kim et al. (31) & $\mathrm{U}-\mathrm{Cd}$ & Cross-sectional & $\begin{array}{l}\text { Male } 63.8 \\
\text { Female } 65.2\end{array}$ & $456 / 630$ & 1,086 & Korea & $\begin{array}{l}\text { Ultrasound bone } \\
\text { densitometer }\end{array}$ \\
\hline Engström et al. (30) & U-Cd & Cross-sectional & $<70$ & $-/ 2,688$ & 2,688 & Sweden & Dual-energy X-ray \\
\hline Shin et al. (29) & U-Cd & Prospective cohort & & $357 / 447$ & 804 & Korea & Dual-energy X-ray \\
\hline Wu et al. (33) & U-Cd & Cross-sectional & 30-90 & & 10,978 & America & \\
\hline Nawrot et al. (28) & U-Cd & Cross-sectional & 45 & 83/- & 83 & Belgium & Dual-energy X-ray \\
\hline Gallagher et al. (27) & U-Cd & Cross-sectional & 67 & $-/ 3,207$ & 3,207 & America & Dual-energy X-ray \\
\hline Wang et al. (26) & U-Cd & Cross-sectional & $\begin{array}{l}\text { Male control } 54.3 \\
\text { Male moderate } 51.1 \\
\text { Male heavy } 55.4 \\
\text { Female control } 50.0 \\
\text { Female moderate } 51.3 \\
\text { Female heavy } 52.4\end{array}$ & $302 / 488$ & 790 & China & $\begin{array}{l}\text { SPA-4 single-photon } \\
\text { absorptiometry }\end{array}$ \\
\hline Alfvén et al. (25) & U-Cd & Cross-sectional & $\begin{array}{l}\text { Environmentally exposed } \\
\text { Male } 52.0 \\
\text { Female } 51.4 \\
\text { Occupationally exposed } \\
\text { Male } 58.4 \\
\text { Female } 56.5\end{array}$ & $520 / 544$ & 1,064 & Sweden & Dual-energy X-ray \\
\hline
\end{tabular}

\section{Selection Criteria}

The articles were independently selected and commented on by two authors. First, the title and abstract were filtered based on the relevance of the topic. After reading the abstract, the full text was screened and articles that will eventually be included in the meta-analysis were selected. Articles that met the inclusion criteria were independently selected by two authors. When it was unclear whether an article should be included, a discussion was conducted with the third author to reach a consensus.

The inclusion criteria were as follows: (1) studies including human subjects; (2) observational studies; (3) studies that reported the relationship between blood or urine $\mathrm{Cd}$ concentration and osteoporosis or bone mass loss, and (4) studies that calculated and reported relative risk (RR), odds ratio (OR), or hazard ratio (HR) and $95 \%$ confidence interval (CI) values.
The exclusion criteria were as follows: (1) Animal experiments; (2) in vitro or laboratory studies; and (3) comments or case reports.

\section{Data Extraction and Quality Assessment}

Two examiners used standardized data collection forms to extract data independently. These differences were resolved through discussions with other investigators and referenced to the original article. The data extracted from each study included the first author's last name, publication year, study type, average age, male to female ratio, sample size, study country, bone density measurement method, blood or urine $\mathrm{Cd}$ concentration, adjusted variables, and the corresponding 95\% CIs-OR estimate. If the OR value of different potential confounding factors was high, the OR value extracted reflected the maximum control of the 
TABLE 2 | Summary characteristics of studies.

\begin{tabular}{|c|c|c|c|c|c|c|c|}
\hline \multicolumn{8}{|c|}{$\mathrm{B}-\mathrm{Cd}$} \\
\hline References & Measured & Type & & $B-C d(\mu g / g)$ & or & $95 \% \mathrm{Cl}$ & Adjustment \\
\hline \multirow[t]{4}{*}{ Lim et al. (24) } & \multirow{4}{*}{$\begin{array}{l}\text { Graphite furnace atomic } \\
\text { absorption spectrometry }\end{array}$} & & Q1 & 0.66 & 1 & & \multirow{4}{*}{$\begin{array}{l}\text { Age, sex, lifestyle behaviors (smoking status, } \\
\text { alcohol drinking, and living region). } \\
\text { sociodemographic factors (educational level, } \\
\text { occupation and family income). }\end{array}$} \\
\hline & & & Q2 & 0.825 & 0.99 & $(0.77-1.26)$ & \\
\hline & & & Q3 & 1.2145 & 1.01 & $(0.79-1.31)$ & \\
\hline & & & Q4 & 1.439 & 1.8 & $(1.35-2.4)$ & \\
\hline \multirow[t]{3}{*}{ Burm et al. (23) } & $\begin{array}{l}\text { Atomic absorption } \\
\text { spectrophotometry }\end{array}$ & Total femur & & 0.83 & 1.81 & $(1.07-3.07)$ & \multirow{3}{*}{$\begin{array}{l}\text { Age, body mass index, height, household income, } \\
\text { alcohol consumption, hypertention, diabetes } \\
\text { mellitus, exercise and urinary cotinine. }\end{array}$} \\
\hline & & Lumbar spine & & 0.83 & 1.17 & $(0.87-1.57)$ & \\
\hline & & Femoral neck & & 0.83 & 1.49 & $(1.1-2.03)$ & \\
\hline \multirow[t]{6}{*}{$\begin{array}{l}\text { Choi and Han } \\
\text { (22) }\end{array}$} & \multirow[t]{6}{*}{$\begin{array}{l}\text { Graphite furnace atomic } \\
\text { absorption spectrometry }\end{array}$} & Non-Obese & & 1 & 1 & & \multirow{6}{*}{$\begin{array}{l}\text { Age, BMl (as a continuous variable), serum } \\
\text { creatinine (as a continuous variable), vitamin D } \\
\text { deficiency [serum } 25(\mathrm{OH}) \mathrm{D}<20 \mathrm{ng} / \mathrm{mL} \text { ], smoking } \\
\text { (current smoker vs. non-smoker), alcohol drinking } \\
\text { (>7 drinks of alcoholic beverage per time, twice or } \\
\text { more in a week: yes or no) and physical activity } \\
\text { (vigorous physical activity for more than } 20 \text { min per } \\
\text { time, three times or more in a week: yes or no). }\end{array}$} \\
\hline & & Non-Obese & Q2 & 1.25 & 0.83 & $(0.51-1.36)$ & \\
\hline & & Non-Obese & Q3 & 1.5 & 0.72 & $(0.42-1.23)$ & \\
\hline & & Obese & Q1 & 1 & 1 & & \\
\hline & & Obese & Q2 & 1.25 & 2.36 & $(0.92-6.08)$ & \\
\hline & & Obese & Q3 & 1.5 & 5.71 & (1.99-16.38) & \\
\hline \multirow[t]{2}{*}{ Chen et al. (21) } & \multirow[t]{2}{*}{$\begin{array}{l}\text { Graphite furnace atomic } \\
\text { absorption spectrometry }\end{array}$} & Male & & 2 & 0.93 & $(0.3-2.74)$ & \multirow[t]{2}{*}{$\begin{array}{l}\text { Age, weight, height, smoking, alcohol and } \\
\text { menopause status (women) }\end{array}$} \\
\hline & & Female & & 2 & 2.5 & $(1.11-5.43)$ & \\
\hline \multirow[t]{4}{*}{ Pollack et al. (20) } & \multirow{4}{*}{$\begin{array}{l}\text { Inductively coupled plasma } \\
\text { mass spectrometry }\end{array}$} & & & & & & \multirow{4}{*}{$\begin{array}{l}\text { Age (continuous), race (white, black, Asian, other), } \\
\text { parity, average caloric intake (continuous), age at } \\
\text { menarche (continuous) }\end{array}$} \\
\hline & & Total hip & & 0.36 & 0.98 & $(0.89-1.07)$ & \\
\hline & & Lumbar spine & & 0.36 & 1.17 & $(0.56-2.46)$ & \\
\hline & & Wrist & & 0.36 & 0.91 & $(0.43-1.94)$ & \\
\hline \multirow[t]{4}{*}{ Cho et al. (19) } & Atomic absorption & & Q1 & 1 & 1 & & \multirow{4}{*}{$\begin{array}{l}\text { Intake of caloric energy and calcium, fish } \\
\text { consumption, and vitamin D level in addition to the } \\
\text { corrections included in model 1. Pb, lead; Hg, } \\
\text { mercury; Cd, cadmium; As, arsenic. }\end{array}$} \\
\hline & spectrophotometry & & Q2 & 1.19 & 1.22 & $(0.65-2.29)$ & \\
\hline & & & Q3 & 1.58 & 1.27 & $(0.68-2.39)$ & \\
\hline & & & Q4 & 1.78 & 0.96 & $(0.51-1.81)$ & \\
\hline \multirow[t]{3}{*}{ Alfvén et al. (18) } & $\begin{array}{l}\text { Inductively coupled plasma } \\
\text { mass spectrometry }\end{array}$ & & Q1 & 0.56 & 1 & & \multirow[t]{3}{*}{ Weight, smoking, } \\
\hline & & & Q2 & 0.84 & 2 & $(1.1-3.9)$ & \\
\hline & & & Q3 & 1.12 & 2.9 & $(1.4-5.8)$ & \\
\hline
\end{tabular}

\section{U-Cd}

\begin{tabular}{|c|c|c|c|c|c|c|c|}
\hline References & Measured & Type & & $\mathrm{U}-\mathrm{Cd}(\mu \mathrm{g} / \mathrm{g})$ & OR & $95 \% \mathrm{Cl}$ & Adjustment \\
\hline \multirow[t]{8}{*}{ Lv et al. (32) } & \multirow{8}{*}{$\begin{array}{l}\text { Inductively coupled plasma } \\
\text { mass spectrometry }\end{array}$} & Total & Q1 & 2.05 & 1 & 1 & \multirow{8}{*}{$\begin{array}{l}\text { Age, gender, BMI, serum albumin, urinary } \mathrm{Ca} \text {, and } \\
\text { urinary U-Alb. }\end{array}$} \\
\hline & & Total & Q2 & 3.01 & 3.07 & $(1.77-5.33)$ & \\
\hline & & Total & Q3 & 6.43 & 4.63 & $(2.68-7.98)$ & \\
\hline & & Total & Q4 & 8.89 & 9.15 & $(5.26-15.94)$ & \\
\hline & & Nonsmokers & Q1 & 2.05 & 1 & & \\
\hline & & Nonsmokers & Q2 & 3.01 & 1.85 & $(0.89-3.86)$ & \\
\hline & & Nonsmokers & Q3 & 6.43 & 3.27 & $(1.6-6.68)$ & \\
\hline & & Nonsmokers & Q4 & 8.89 & 9.29 & $(4.56-18.93)$ & \\
\hline $\begin{array}{l}\text { Van Larebekea } \\
\text { et al. (34) }\end{array}$ & $\begin{array}{l}\text { Inductively coupled plasma } \\
\text { mass spectrometry }\end{array}$ & Female & & 0.625 & 1.26 & $(0.97-1.63)$ & BMI, education status, and exercise level \\
\hline \multirow[t]{6}{*}{ Kim et al. (31) } & \multirow{6}{*}{$\begin{array}{l}\text { Atomic absorption } \\
\text { spectrophotometer }\end{array}$} & Male & Q1 & $\leq 5$ & 1 & & \multirow{4}{*}{$\begin{array}{l}\text { Age, smoking status, alcohol intake, BMI, diabetes, } \\
\text { hypertension, and menopause (only females). }\end{array}$} \\
\hline & & Male & Q2 & $>5$ & 3.12 & $(1.36-7.14)$ & \\
\hline & & Female & Q1 & $\leq 5$ & 1 & & \\
\hline & & Female & Q2 & $>5$ & 2.8 & $(1.6-4.9)$ & \\
\hline & & Total & Q1 & $\leq 5$ & 1 & & \multirow{2}{*}{$\begin{array}{l}\text { Age, sex (only total subjects), smoking status, } \\
\text { alcohol, intake, BMI, diabetes, hypertension, and } \\
\text { menopause (only females). }\end{array}$} \\
\hline & & Total & Q2 & $>5$ & 1.54 & $(1.05-2.25)$ & \\
\hline
\end{tabular}


TABLE 2 | Continued

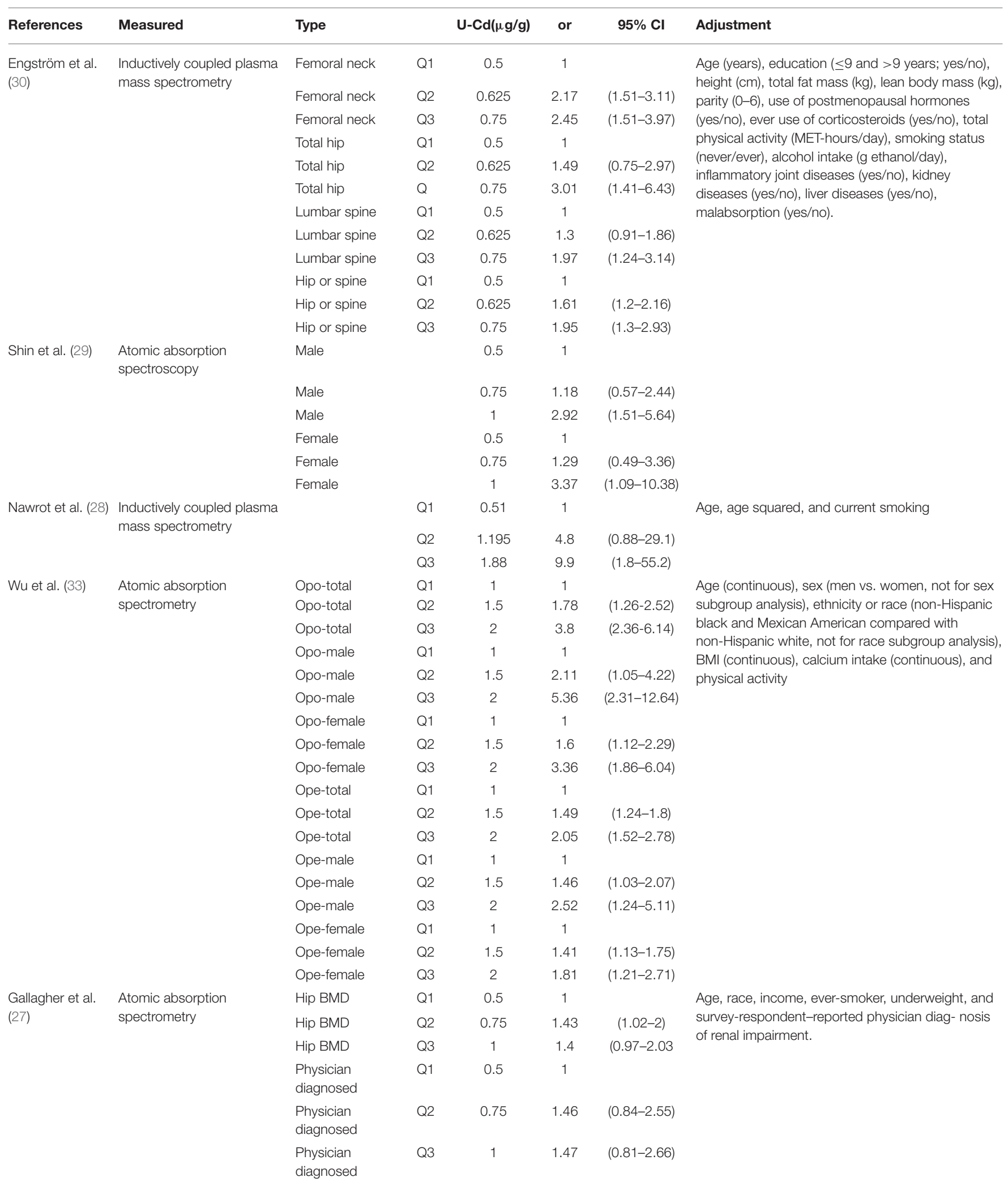


TABLE 2 | Continued

\begin{tabular}{|c|c|c|c|c|c|c|c|}
\hline References & Measured & Type & & $\mathrm{U}-\mathrm{Cd}(\mu \mathrm{g} / \mathrm{g})$ & or & $95 \% \mathrm{Cl}$ & Adjustment \\
\hline \multirow[t]{6}{*}{ Wang et al. (26) } & $\begin{array}{l}\text { Atomic absorption } \\
\text { spectrophotometry }\end{array}$ & Male & Q1 & 1.58 & 1 & & \\
\hline & & Male & Q2 & 2.27 & 0.75 & $(0.1-4.5)$ & \\
\hline & & Male & Q3 & 9.2 & 1.72 & $(0.5-5.9)$ & \\
\hline & & Females & Q1 & 1.79 & 1 & & \\
\hline & & Females & Q2 & 4.45 & 1.38 & $(0.7-2.8)$ & \\
\hline & & Females & Q3 & 12.86 & 2.09 & $(1.1-4)$ & \\
\hline \multirow[t]{3}{*}{ Alfvén et al. (25) } & $\begin{array}{l}\text { Inductively coupled plasma } \\
\text { mass spectrometry }\end{array}$ & & Q1 & 0.5 & 1 & & \\
\hline & & & Q2 & 1.75 & 1.2 & $(0.82-1.8$ & \\
\hline & & & Q3 & 3 & 2.5 & $(1.2-5.2)$ & \\
\hline
\end{tabular}

potential confounding factors. When required, the authors of the preliminary study were contacted for more information.

\section{Statistical Analyses}

Research data consisting of the OR of blood or urine Cd concentration and the risk of osteoporosis or osteopenia were included for analysis, and the size of the impact was expressed as 95\% CI; a random-effects model was implemented (13). Cochran Q statistics and $I^{2}$ statistics were used to assess the heterogeneity between studies (14). $I^{2}$ values of $25 \%$, 50, and $75 \%$ were considered low, medium, and high heterogeneity, respectively (15). Subgroup analysis separately assessed the relationship between blood and urine Cd concentrations and related research characteristics (sex and degree of osteoporosis) of the risk of osteoporosis or osteopenia, as a possible source of heterogeneity. Funnel chart asymmetry was used to test publication bias, and Begg's and Egger's tests were employed to measure funnel chart asymmetry (16). A "cut and fill" assessment was conducted to further evaluate the possible impact of publication bias in our meta-analysis. This method reflects the empirical research that causes funnel graph asymmetry by conservatively attributing to hypothetical negative unpublished research (17). Osteoporosis was classified as normal (T-score $>-1.0)$, osteopenia $(-2.5 \leq$ T-score $\leq$ -1.0 ), and osteoporosis (T-score $<-2.5$ ). All statistical analyses were performed using STATA 12 (StataCorp, College Station, TX, USA).

\section{RESULTS}

\section{Search Results}

Figure 1 shows the process of document screening, research selection, and exclusion. The initial database search included 336 articles. After reading the abstract and title, 342 articles were excluded. The quality of the remaining 24 articles was evaluated, and seven articles that did not meet the inclusion criteria were excluded. Finally, 17 articles were selected for the meta-analysis, of which seven were focused on blood Cd concentrations (18-24) and 10 on urine Cd concentrations (25-34).

\section{Research Characteristics}

A total of 29,488 people from 17 studies were included in the analysis. Seven studies measured blood Cd concentration, involving a total of 6,864 subjects, with 4,191 men and 2,673 women. Only two articles were related to osteoporosis and the remaining five articles were related to osteoporosis and osteopenia. Meanwhile, 10 studies measured urine $\mathrm{Cd}$ concentration, involving 22,624 people, with 2,229 males and 9,417 females. Six articles involved osteoporosis, two involved osteopenia, and two involved osteoporosis and osteopenia. The risk estimates provided by most studies were adjusted for age, sex, smoking, body mass index, physical activity, and weight.

Tables 1, 2 summarize the characteristics of the study and participants.

\section{Blood Cadmium Concentration Level and the Risk of Osteoporosis or Osteopenia}

Figure 2A shows the results of blood Cd meta-analysis. Blood $\mathrm{Cd}$ concentration increased the risk of osteoporosis or osteopenia (OR $=1.21,95 \% \mathrm{CI}: 0.84-1.58)$, and the heterogeneity between different studies was moderate $\left(I^{2}=57.9 \%, P=0.015\right)$. The comprehensive estimate of the risk of blood Cd concentration events did not change substantially without any research conducted through sensitivity analysis (Figure 3A).

\section{Urinary Cadmium Concentration Level and the Risk of Osteoporosis or Osteopenia}

Figure 2B shows the results of the urine $\mathrm{Cd}$ meta-analysis. Urinary Cd concentration increased the risk of osteoporosis or osteopenia ( $\mathrm{OR}=1.80,95 \% \mathrm{CI}: 1.42-2.18)$. The heterogeneity between different studies was moderate $\left(I^{2}=45.7 \%, P=\right.$ 0.032). The comprehensive estimate of the risk of urinary $\mathrm{Cd}$ concentration events did not change substantially after excluding any research conducted through sensitivity analysis (Figure 3B).

\section{Publication Bias}

For the relationship between blood $\mathrm{Cd}$ concentration and osteoporosis and osteopenia, the Begg's test $(P=0.297, z=$ $1.04)$ and Egger's test $(P=0.396)$ showed no publication bias, whereas for the relationship between urine $\mathrm{Cd}$ concentration and 
A

Study

OR $(95 \% \mathrm{Cl})$

Lim et al (2016)

Burm et al (2015)

Choi et al(non-ob) (2015)

Choi et al(ob) (2015)

Chen et al(male) (2014)

Chen et al(female) (2014)

Pollack et al (2013)

Cho et al (2012)

Alfvén et al (2002)

Overall $(\mathrm{l}$-squared $=57.9 \%, p=0.015)$

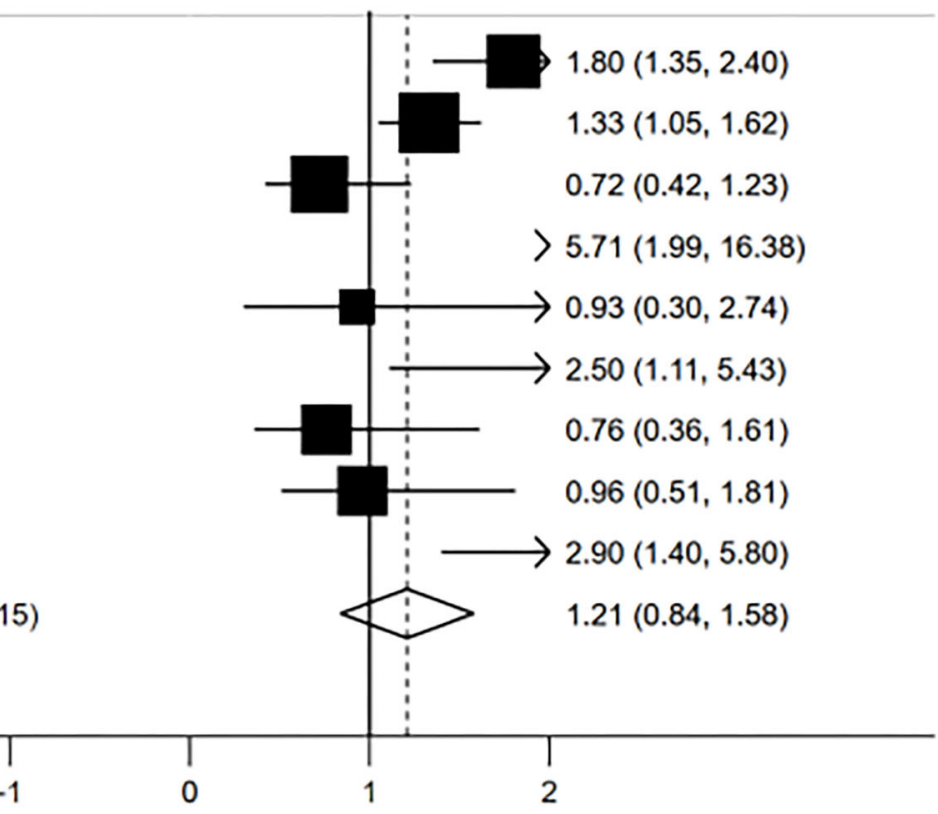

B

Study

OR $(95 \% \mathrm{Cl})$

Lv et al (2017)

Larebekea et al(female) (2015)

Kim et al (2014)

Engstro " $m$ et al (2011)

Shin et al(male) (2011)

Shin et al(female) (2011)

Nawrot et al (2010)

Wu et al (2010)

Wu et al (2010)

Gallagher et al (2008)

Gallagher et al (2008)

Wang et al(male) (2003)

Wang et al(female) (2003)

ALFVE' $N$ et al (2000)

Overall (I-squared $=45.7 \%, p=0.032$ )

NTE: Weins are from ranoom etecss anaysis

$-5 \quad-2.5$

FIGURE 2 | The forest plot for studies on the concentration of blood Cd and osteoporosis or osteopenia (A), Urinary Cd concentration and osteoporosis or osteopenia (B). 
A

Filled funnel plot with pseudo $95 \%$ confidence limits

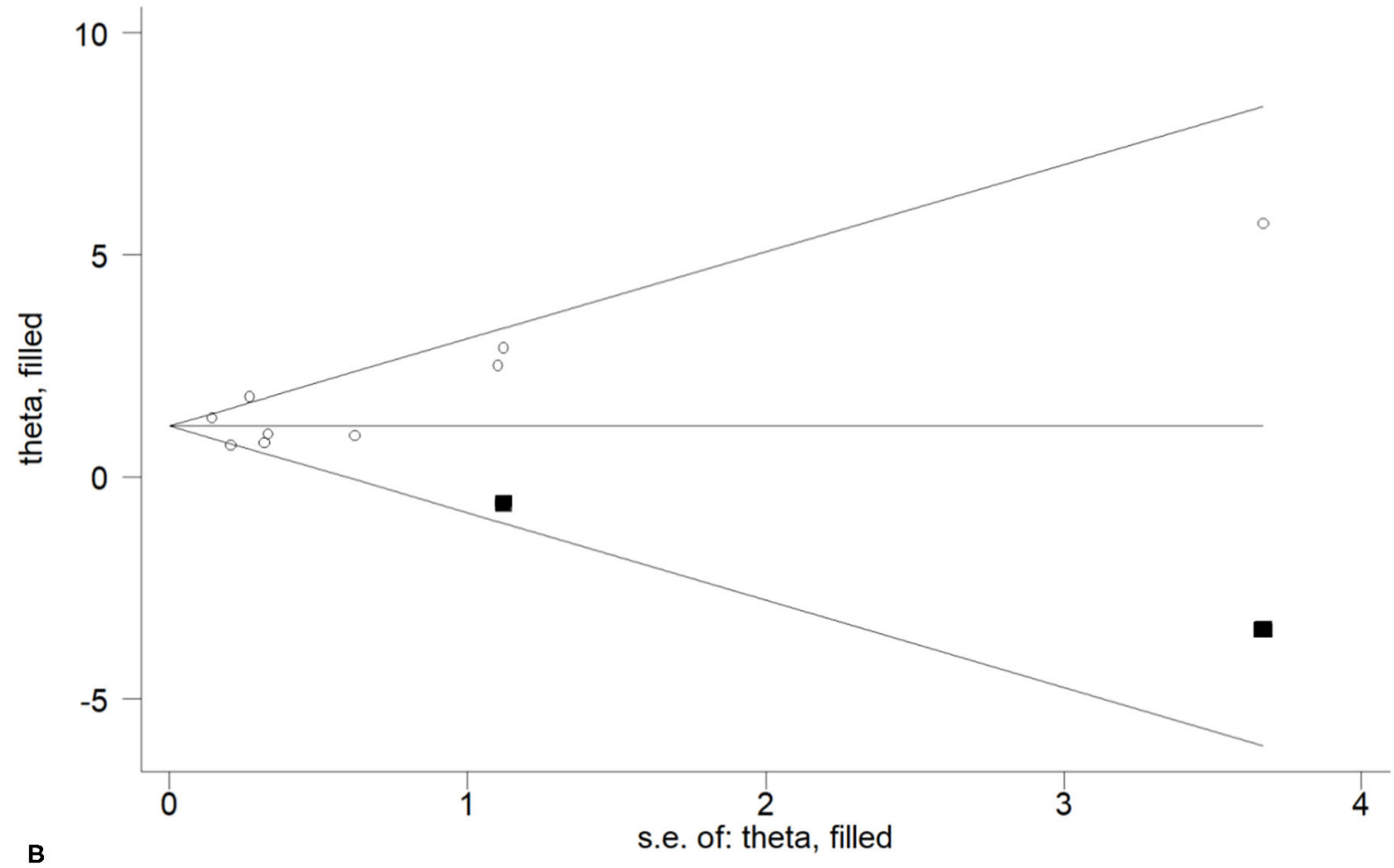

Filled funnel plot with pseudo $95 \%$ confidence limits

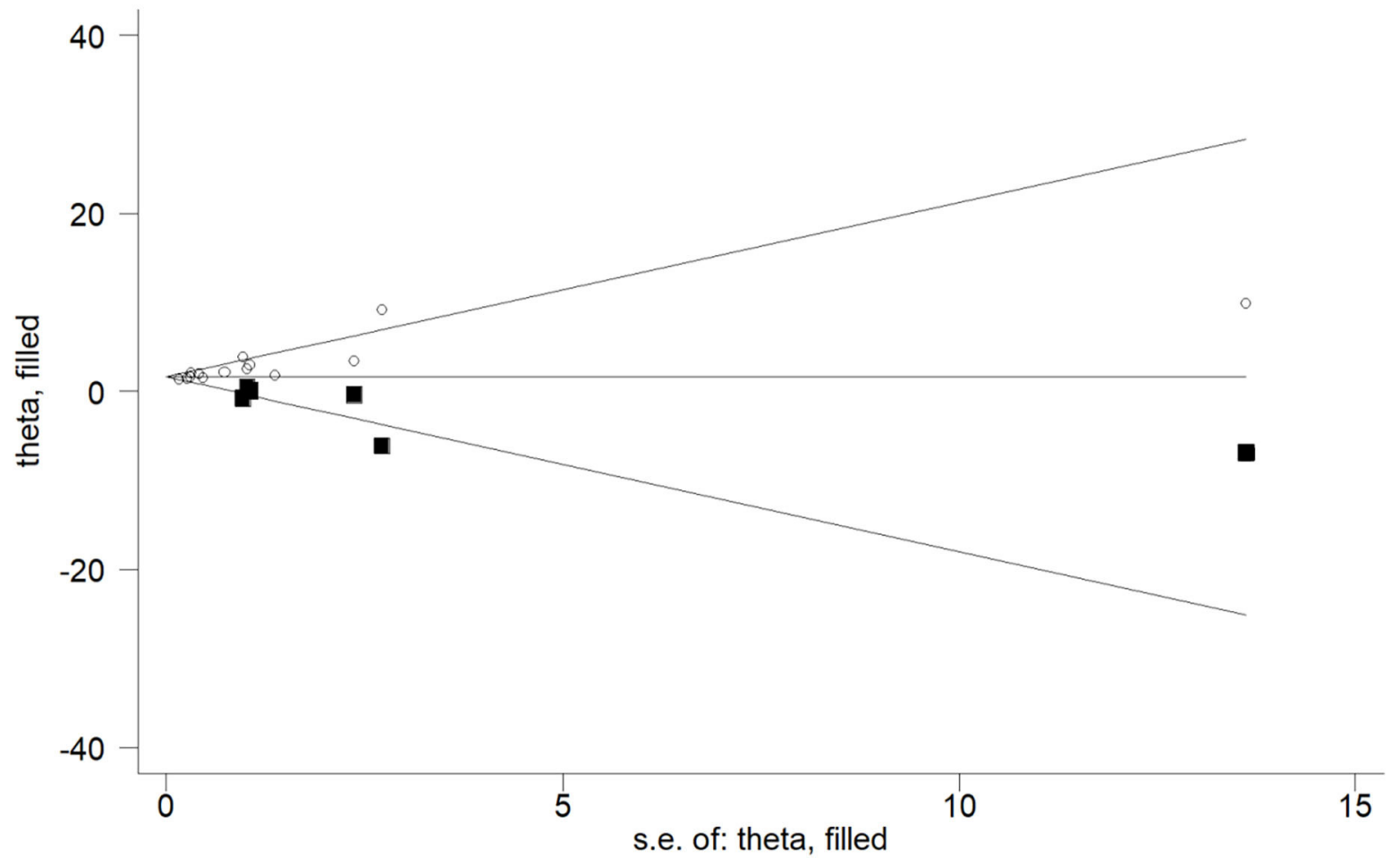

FIGURE 3 | Trim and fill funnel plot for meta-analysis of the association between Blood Cd concentration and osteoporosis or osteopenia (A), Urinary Cd concentration and osteoporosis or osteopenia (B). 
A

Meta-analysis estimates, given named study is omitted

| Lower Cl Limit oEstimate

Lim et al (2016)

Burm et al (2015)

Choi et al(non-ob) (2015)

Choi et al(ob) (2015)

Chen et al(male) (2014)

Chen et al(female) (2014)

Pollack et al (2013)

Cho et al (2012)

Alfvén et al (2002

B

0.83

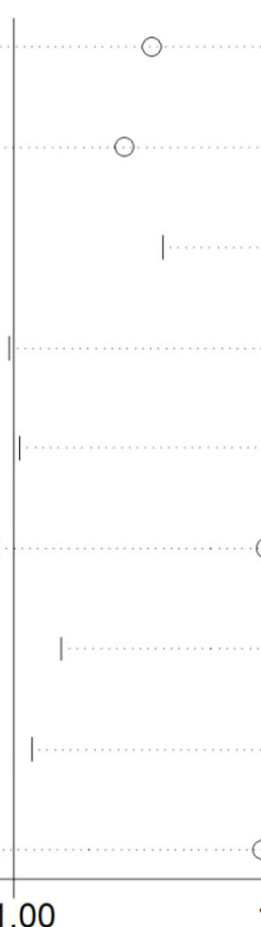

1.00
| Upper Cl Limit

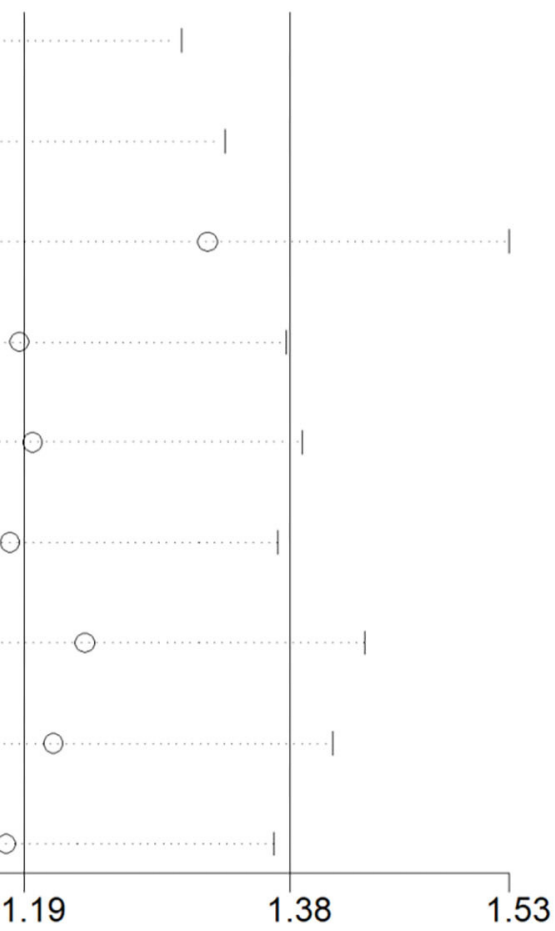

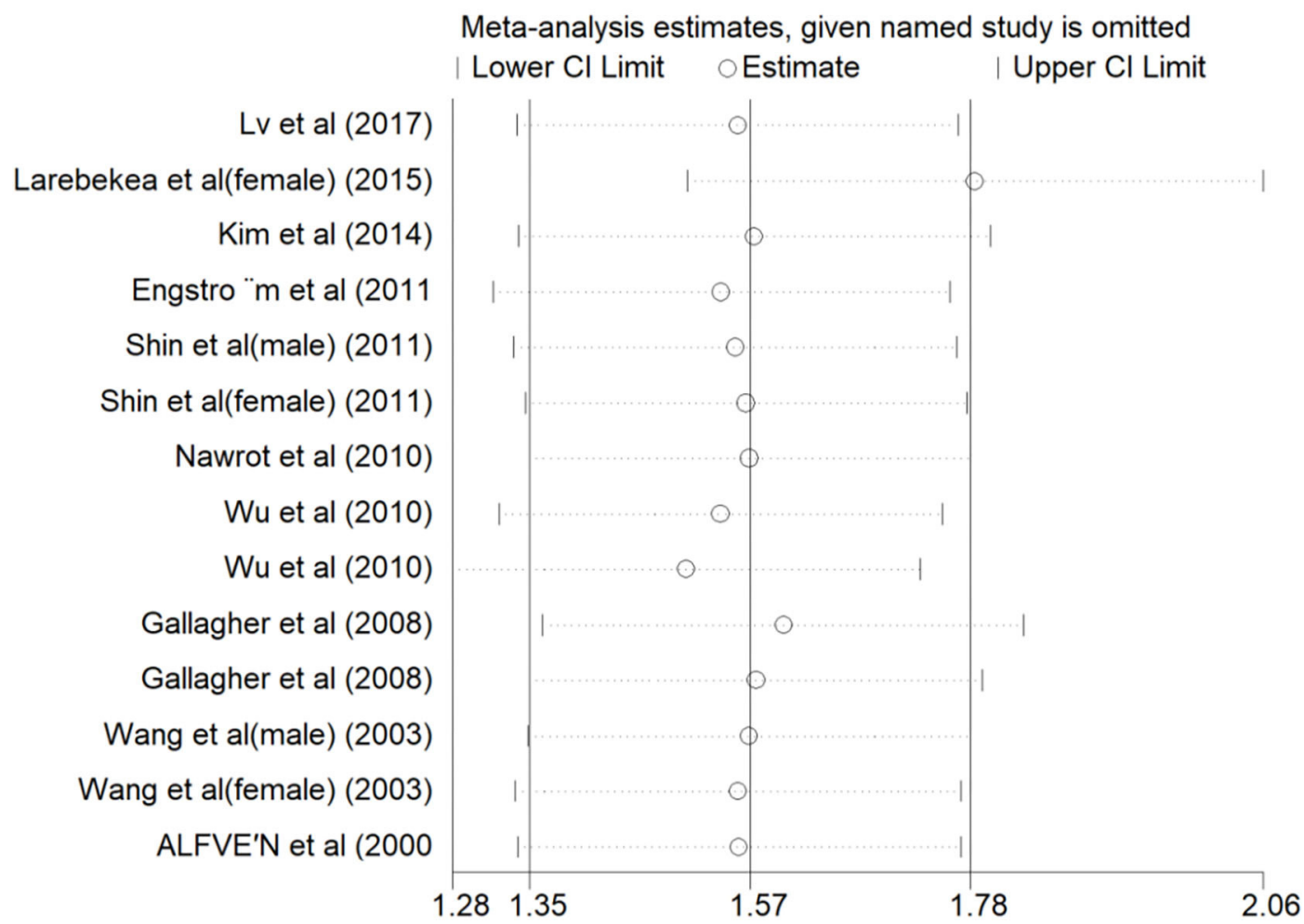

FIGURE 4 | Sensitivity analysis of Blood Cd concentration and osteoporosis or osteopenia (A), Urinary Cd concentration and osteoporosis or osteopenia (B) 
osteoporosis and osteopenia, the Begg's test $(P=0.021, z=2.31)$ and Egger's test $(P=0.000)$ showed publication bias. In order to further evaluate publication bias, we adopted the method of pruning and filling. Through computer filling, the results after correction for publication bias did not change (Estimate $=1.600$; 95\% CI: 1.166-2.034) (Figure 4).

\section{Subgroup Analysis}

The correlation between blood Cd concentration and osteoporosis and osteopenia was analyzed by subgroup analysis. The results are shown in Table 3. Sex was evaluated as a source of heterogeneity. Blood Cd concentration was associated with an increased risk of osteoporosis and osteopenia for both males and females (male OR $=1.05,95 \%$ CI: $0.54-1.57, I^{2}=59.9 \%$, $P=0.058$; female OR $=0.94,95 \%$ CI: $0.44-1.44, \mathrm{I}^{2}=13.8 \%$, $P=0.313)$. In addition, a subgroup analysis of the degree of osteoporosis was conducted, with the following categories: normal (T-score $>-1.0)$, osteopenia $(-2.5 \leq$ T-score $\leq-1.0)$, and osteoporosis (T-score $<-2.5$ ). Blood Cd concentration was associated with an increased risk of osteoporosis (T-score $\left.\leq-1.0, \mathrm{OR}=1.38,95 \% \mathrm{CI}: 0.96-1.81, I^{2}=48.5 \%, P=0.084\right)$ and osteopenia (T-score $<-2.5, \mathrm{OR}=0.81,95 \% \mathrm{CI}: 0.43-1.19$, $\left.I^{2}=7.9 \%, P=0.338\right)$.

The correlation between urine Cd concentration and the risk of osteoporosis and osteopenia was analyzed using subgroup analysis. A subgroup analysis of sex revealed that urine Cd concentration was associated with an increased risk of osteoporosis and osteopenia for both males and females (male OR $=2.74,95 \%$ CI: $1.62-3.86, I^{2}=0.00 \%, P=0.855$; female $\mathrm{OR}=1.62$, 95\% CI: $\left.1.29-1.94, I^{2}=25.1 \%, P=0.22\right)$. For the analysis of the degree of osteoporosis, urine Cd concentration was associated with an increased risk of osteoporosis $(-2.5 \leq$ T-score $\leq-1.0, \mathrm{OR}=2.03,95 \% \mathrm{CI}: 1.38-2.69, I^{2}=0.0 \%$, $P=0.657)$ and osteopenia (T-score $<-2.5$, OR $=1.86,95 \% \mathrm{CI}$ : $\left.1.36-2.36, I^{2}=47.7 \%, P=0.033\right)$.

\section{DISCUSSION}

The results of our meta-analysis showed that blood Cd concentration was not associated with the risk of osteoporosis and osteopenia. However, urine Cd concentration was associated with an increased risk of osteoporosis and osteopenia.

In the 1840s, a "Itai-itai" characterized by multiple fractures and bone pain caused by $\mathrm{Cd}$ pollution was discovered in Japan. The patient's radiograph showed signs of false fractures of osteomalacia and severe decalcification during osteoporosis, as well as signs of proteinuria and other renal damage (35). After $\mathrm{Cd}$ enters the body, the kidneys and bones are the main target organs. About $50-80 \%$ of $\mathrm{Cd}$ accumulate in the bones and kidneys, leading to osteoporosis and also causing severe glomerular and tubular dysfunction (36). The effect on bones is considered to be the late manifestation of Cd toxicity. Regarding the mechanism of Cd specifically causing osteoporosis, Liu $\mathrm{W}$ et al. found that $\mathrm{Cd}$ can increase osteoblast apoptosis through autophagy (37). Arbon's study and other studies have also shown that $\mathrm{Cd}$ can directly inhibit osteoblasts and cause osteoporosis (38). Ma et al. and other studies have shown that
TABLE 3 | Subgroup analysis to investigate differences between studies included in meta-analysis.

\begin{tabular}{lcccc}
\hline Type & studies & OR (95\% Cl) & $\boldsymbol{I}^{\mathbf{2}}$ & $\boldsymbol{P}$-value \\
\hline B-Cd & & & & \\
$\begin{array}{l}\text { Osteoporosis and Osteopenia } \\
\text { Osteoporosis }\end{array}$ & 5 & $1.38(0.96-1.81)$ & $48.5 \%$ & 0.084 \\
B-Cd & 2 & $0.81(0.43-1.19)$ & $7.9 \%$ & 0.338 \\
Male & & & & \\
Female & 3 & $1.05(0.54-1.57)$ & $59.9 \%$ & 0.058 \\
U-cd & 3 & $0.94(0.44-1.44)$ & $13.8 \%$ & 0.313 \\
Osteoporosis & & & & \\
Osteopenia & 8 & $1.86(1.36-2.36)$ & $47.7 \%$ & 0.033 \\
U-Cd & 2 & $2.03(1.38-2.69)$ & $0.0 \%$ & 0.657 \\
$\begin{array}{l}\text { Male } \\
\text { Female }\end{array}$ & 5 & $2.74(1.62-3.86)$ & $0.0 \%$ & 0.855 \\
& 7 & $1.62(1.29-1.94)$ & $25.1 \%$ & 0.22 \\
\hline
\end{tabular}

Cd exposure significantly inhibits the differentiation of bone marrow mesenchymal stem cells, osteoblasts, and osteoclasts and promotes the occurrence of osteoporosis by promoting osteoblast apoptosis (39). In general, the pathophysiology of Cdinduced osteoporosis involves the inhibition of the accumulation of peak bone mass during growth. This adversely affects the maintenance of bone mass during bone maturation and enhances age-related osteopenia.

In an investigation of Cd-induced osteoporosis and osteopenia, Chen et al. found that high concentrations of cumulative $\mathrm{Cd}$ intake were associated with an increased incidence of osteoporosis and fractures in women. In men, similar trends were observed, but no statistical significance was found (40). In a study involving Japanese women, Horiguchi et al. concluded that the environmental level of $\mathrm{Cd}$ exposure was not enough to induce renal tubular dysfunction and would not affect bone mineral density (41). In addition to studies on adults, Sughis et al. found a consistent association between urine $\mathrm{Cd}$ concentration and children's bone resorption and bone demineralization in a study of children aged 8-12 years (42). In a Swedish study, Wallin et al. evaluated the effect of Cd concentration in 109 living kidneys on osteoporosis and concluded a negative correlation between kidney $\mathrm{Cd}$ and bone mineral density (43); however, there are very few studies on this measurement method. The current measurement method of Cd in the human body still uses blood and urine $\mathrm{Cd}$ concentrations as the most common biomarkers of $\mathrm{Cd}$ exposure. Urinary $\mathrm{Cd}$ mainly reflects $\mathrm{Cd}$ accumulation in the kidney and is also a manifestation of renal damage and osteoporosis in the later stage, whereas blood Cd shows acute and chronic exposure. The concentration of the two is essential for bone density.

There is no clear conclusion on the relationship between $\mathrm{Cd}$ concentration and osteoporosis and osteopenia, and there are few meta-analyses on $\mathrm{Cd}$ and bone health. Cheng et al. conducted a meta-analysis of $\mathrm{Cd}$ exposure and fracture risk and performed a subgroup analysis of urinary and blood $\mathrm{Cd}$, and the results showed that $\mathrm{Cd}$ exposure may be a risk factor for any increased risk of fracture (44). In a meta-analysis on heavy 
metal concentration and osteoporosis, Jalili et al. mentioned that blood Cd is a risk factor for osteoporosis, whereas urinary Cd is not associated with osteoporosis (45). After careful comparison of reference data, there is a misclassification of urine and blood $\mathrm{Cd}$ data in the article, with very few studies evaluating urinary Cd concentrations; thus the article's heterogeneity makes the results questionable.

\section{Advantages and Limitations}

To the best of our knowledge, this is the first meta-analysis to explore the relationship between blood and urine $\mathrm{Cd}$ concentration and osteoporosis and osteopenia. In our study, a total of 29,488 people were included, and the sample heterogeneity was small. At the same time, a subgroup analysis was conducted based on men and women and the degree of osteoporosis.

However, our research also has certain limitations. First, available research on $\mathrm{Cd}$ and osteoporosis is limited, which can imply that the relationship between $\mathrm{Cd}$ concentrations and osteoporosis and osteopenia is not sufficiently convincing. Second, observational studies have inherent limitations, such as selection bias and recall or memory bias. In addition, blood and urine $\mathrm{Cd}$ concentrations and the risk of osteoporosis will be affected by factors such as age. Finally, the studies included in this study may be affected by population, influence of statistical characteristics, limitations of the detection method, and other factors. For these reasons, we recommend our conclusions should be interpreted conservatively.

\section{Conclusion}

Our research indicates that while urine cadmium $(\mathrm{Cd})$ concentration may be related to increased risk of osteoporosis and osteopenia, blood Cd concentration may not. Therefore, compared to blood $\mathrm{Cd}$ concentration, urine $\mathrm{Cd}$ concentration may be more reliable as a risk factor for osteoporosis

\section{REFERENCES}

1. Willson T, Nelson SD, Newbold J, Nelson RE, LaFleur J. The clinical epidemiology of male osteoporosis: a review of the recent literature. Clin Epidemiol. (2015) 7:65-76. doi: 10.2147/CLEP.S40966

2. Svedbom A, Hernlund E, Ivergård M, Compston J, Cooper C, Stenmark J, et al. Osteoporosis in the European Union: a compendium of country-specific reports. Arch Osteoporos. (2013) 8:137. doi: 10.1007/s11657-013-0137-0

3. Scimeca M, Feola M, Romano L, Rao C, Gasbarra E, Bonanno E, et al. Heavy metals accumulation affects bone microarchitecture in osteoporotic patients. Environ Toxicol. (2017) 32:1333-42. doi: 10.1002/tox.22327

4. Saltman PD, Strause LG. The role of trace minerals in osteoporosis. J Am Coll Nutr. (1993) 12:384-9. doi: 10.1080/07315724.1993.10718327

5. Sheng D, Wen X, Wu J, Wu M, Yu H, Zhang C. Comprehensive probabilistic health risk assessment for exposure to arsenic and cadmium in groundwater. Environ Manage. (2021) 67:779-92. doi: 10.1007/s00267-021-01431-8

6. Genchi G, Sinicropi MS, Lauria G, Carocci A, Catalano A. The effects of cadmium toxicity. Int J Environ Res Public Health. (2020) 17:3782. doi: 10.3390/ijerph17113782

7. Chen X, Zhu G, Jin T, Zhou Z, Gu S, Qiu J, et al. Cadmium stimulates the osteoclastic differentiation of RAW264.7 cells in presence of osteoblasts. Biol Trace Elem Res. (2012) 146:349-53. doi: 10.1007/s12011-0119256-x and osteopenia. This result should be interpreted with caution. Currently. research on the relationship between Cd concentration and osteoporosis and osteopenia is limited, thus, further large, high-quality prospective studies are required to elucidate the relationship between $\mathrm{Cd}$ concentration and osteoporosis and osteopenia.

\section{DATA AVAILABILITY STATEMENT}

The datasets presented in this study can be found in online repositories. The names of the repository/repositories and accession number(s) can be found in the article/supplementary material.

\section{AUTHOR CONTRIBUTIONS}

BY and HL designed the meta-analysis. HL, MZ, and JM performed the literature retrieval and the data extraction. DL and LH contributed to writing the article. All authors read and approved the final manuscript.

\section{FUNDING}

This work was financially supported through grants from the Traditional Chinese Medicine Technology Development Plan of Shandong Province (2019-0154), the Clinical Medical Science and Technology Innovation Program of the Jinan Science and Technology Bureau (202019156), and the grant from the Natural Science Foundation of Shandong Province (ZR2016HM43).

\section{ACKNOWLEDGMENTS}

We would like to thank Editage (www.editage.cn) for English language editing.
8. Bhattacharyya MH. Cadmium osteotoxicity in experimental animals: mechanisms and relationship to human exposures. Toxicol Appl Pharmacol. (2009) 238:258-65. doi: 10.1016/j.taap.2009.05.015

9. Brzóska MM, Moniuszko-Jakoniuk J. Low-level lifetime exposure to cadmium decreases skeletal mineralization and enhances bone loss in aged rats. Bone. (2004) 35:1180-91. doi: 10.1016/j.bone.2004.07.010

10. Songprasert N, Sukaew T, Kusreesakul K, Swaddiwudhipong W, Padungtod C, Bundhamcharoen K. Additional burden of diseases associated with cadmium exposure: a case study of cadmium contaminated rice fields in Mae Sot District, Tak Province, Thailand. Int J Environ Res Public Health. (2015) 12:9199-217. doi: 10.3390/ijerph120809199

11. Li X, Li R, Yan J, Song Y, Huo J, Lan Z, et al. Co-exposure of cadmium and lead on bone health in a southwestern Chinese population aged 40-75 years. J Appl Toxicol. (2020) 40:352-62. doi: 10.1002/jat.3908

12. Trzcinka-Ochocka M, Jakubowski M, Szymczak W, Janasik B, Brodzka R. The effects of low environmental cadmium exposure on bone density. Environ Res. (2010) 110:286-93. doi: 10.1016/j.envres.2009.12.003

13. DerSimonian R, Laird N. Meta-analysis in clinical trials. Control Clin Trials. (1986) 7:177-88. doi: 10.1016/0197-2456(86)90046-2

14. Higgins JP, Thompson SG, Deeks JJ, Altman DG. Measuring inconsistency in meta-analyses. BMJ. (2003) 327:557-60. doi: 10.1136/bmj.327.7414.557

15. Higgins JP, Thompson SG. Quantifying heterogeneity in a meta-analysis. Stat Med. (2002) 21:1539-58. doi: 10.1002/sim.1186 
16. Egger M, Davey Smith G, Schneider M, Minder C. Bias in metaanalysis detected by a simple, graphical test. BMJ. (1997) 315:629-34. doi: 10.1136/bmj.315.7109.629

17. Peters JL, Sutton AJ, Jones DR, Abrams KR, Rushton L. Performance of the trim and fill method in the presence of publication bias and between-study heterogeneity. Stat Med. (2007) 26:4544-62. doi: 10.1002/sim.2889

18. Alfvén T, Järup L, Elinder CG. Cadmium and lead in blood in relation to low bone mineral density and tubular proteinuria. Environ Health Perspect. (2002) 110:699-702. doi: 10.1289/ehp.02110699

19. Cho GJ, Park HT, Shin JH, Hur JY, Kim SH, Lee KW, et al. The relationship between blood mercury level and osteoporosis in postmenopausal women. Menopause. (2012) 19:576-81. doi: 10.1097/gme.0b013e3182377294

20. Pollack AZ, Mumford SL, Wactawski-Wende J, Yeung E, Mendola P, Mattison $\mathrm{DR}$, et al. Bone mineral density and blood metals in premenopausal women. Environ Res. (2013) 120:76-81. doi: 10.1016/j.envres.2012.06.001

21. Chen X, Wang K, Wang Z, Gan C, He P, Liang Y, et al. Effects of lead and cadmium co-exposure on bone mineral density in a Chinese population. Bone. (2014) 63:76-80. doi: 10.1016/j.bone.2014.02.017

22. Choi WJ, Han SH. Blood cadmium is associated with osteoporosis in obese males but not in non-obese males: The Korea National Health and Nutrition Examination Survey 2008-2011. Int J Environ Res Public Health. (2015) 12:12144-57. doi: 10.3390/ijerph121012144

23. Burm E, Ha M, Kwon HJ. Association between blood cadmium level and bone mineral density reduction modified by renal function in young and middle-aged men. J Trace Elem Med Biol. (2015) 32:60-5. doi: 10.1016/j.jtemb.2015.06.002

24. Lim HS, Lee HH, Kim TH, Lee BR. Relationship between heavy metal exposure and bone mineral density in Korean Adult. J Bone Metab. (2016) 23:223-31. doi: 10.11005/jbm.2016.23.4.223

25. Alfvén T, Elinder CG, Carlsson MD, Grubb A, Hellström L, Persson B, et al. Low-level cadmium exposure and osteoporosis. J Bone Miner Res. (2000) 15:1579-86. doi: 10.1359/jbmr.2000.15.8.1579

26. Wang $H$, Zhu G, Shi Y, Weng S, Jin T, Kong Q, et al. Influence of environmental cadmium exposure on forearm bone density. J Bone Miner Res. (2003) 18:553-60. doi: 10.1359/jbmr.2003.18.3.553

27. Gallagher CM, Kovach JS, Meliker JR. Urinary cadmium and osteoporosis in U.S. Women $>$ or $=50$ years of age: NHANES 1988-1994 and 1999-2004. Environ Health Perspect. (2008) 116:1338-43. doi: 10.1289/ehp.11452

28. Nawrot T, Geusens P, Nulens TS, Nemery B. Occupational cadmium exposure and calcium excretion, bone density, and osteoporosis in men. J Bone Miner Res. (2010) 25:1441-5. doi: 10.1002/jbmr.22

29. Shin M, Paek D, Yoon C. The relationship between the bone mineral density and urinary cadmium concentration of residents in an industrial complex. Environ Res. (2011) 111:101-9. doi: 10.1016/j.envres.2010.11.010

30. Engström A, Michaëlsson K, Suwazono Y, Wolk A, Vahter M, Akesson A. Long-term cadmium exposure and the association with bone mineral density and fractures in a population-based study among women. J Bone Miner Res. (2011) 26:486-95. doi: 10.1002/jbmr.224

31. Kim YD, Yim DH, Eom SY, Moon SI, Park CH, Kim GB, et al. Differences in the susceptibility to cadmium-induced renal tubular damage and osteoporosis according to sex. Environ Toxicol Pharmacol. (2014) 38:2728. doi: 10.1016/j.etap.2014.06.002

32. Lv Y, Wang $\mathrm{P}$, Huang $\mathrm{R}$, Liang $\mathrm{X}$, Wang $\mathrm{P}$, Tan J, et al. Cadmium exposure and osteoporosis: a population-based study and benchmark dose estimation in Southern China. J Bone Miner Res. (2017) 32:1990-2000. doi: 10.1002/jbmr.3151

33. Wu Q, Magnus JH, Hentz JG. Urinary cadmium, osteopenia, and osteoporosis in the US population. Osteoporos Int. (2010) 21:1449-54. doi: 10.1007/s00198-009-1111-y
34. Van Larebeke N, Sioen I, Hond ED, Nelen V, Van de Mieroop E, Nawrot T, et al. Internal exposure to organochlorine pollutants and cadmium and selfreported health status: a prospective study. Int J Hyg Environ Health. (2015) 218:232-45. doi: 10.1016/j.ijheh.2014.11.002

35. Nordberg GF. Cadmium and health in the 21st century-historical remarks and trends for the future. Biometals. (2004) 17:485-9. doi: 10.1023/B:BIOM.0000045726.75367.85

36. Nishijo M, Nakagawa H, Suwazono Y, Nogawa K, Kido T. Causes of death in patients with Itai-itai disease suffering from severe chronic cadmium poisoning: a nested case-control analysis of a follow-up study in Japan. BMJ Open. (2017) 7:e015694. doi: 10.1136/bmjopen-2016015694

37. Liu W, Dai N, Wang Y, Xu C, Zhao H, Xia P, et al. Role of autophagy in cadmium-induced apoptosis of primary rat osteoblasts. Sci Rep. (2016) 6:20404. doi: 10.1038/srep20404

38. Arbon KS, Christensen CM, Harvey WA, Heggland SJ. Cadmium exposure activates the ERK signaling pathway leading to altered osteoblast gene expression and apoptotic death in Saos-2 cells. Food Chem Toxicol. (2012) 50:198-205. doi: 10.1016/j.fct.2011.10.031

39. Ma Y, Ran D, Zhao H, Song R, Zou H, Gu J, et al. Cadmium exposure triggers osteoporosis in duck via P2X7/PI3K/AKT-mediated osteoblast and osteoclast differentiation. Sci Total Environ. (2021) 750:141638. doi: $10.1016 /$ j.scitotenv.2020.141638

40. Chen X, Wang Z, Zhu G, Nordberg GF, Jin T, Ding X. The association between cumulative cadmium intake and osteoporosis and risk of fracture in a Chinese population. J Expo Sci Environ Epidemiol. (2019) 29:435-43. doi: 10.1038/s41370-018-0057-6

41. Horiguchi H, Oguma E, Sasaki S, Miyamoto K, Ikeda Y, Machida M, et al. Environmental exposure to cadmium at a level insufficient to induce renal tubular dysfunction does not affect bone density among female Japanese farmers. Environ Res. (2005) 97:83-92. doi: 10.1016/j.envres.2004. 03.004

42. Sughis M, Penders J, Haufroid V, Nemery B, Nawrot TS. Bone resorption and environmental exposure to cadmium in children: a cross-sectional study. Environ Health. (2011) 10:104. doi: 10.1186/1476-069X-10-104

43. Wallin M, Sallsten G, Fabricius-Lagging E, Öhrn C, Lundh T, Barregard L. Kidney cadmium levels and associations with urinary calcium and bone mineral density: a cross-sectional study in Sweden. Environ Health. (2013) 12:22. doi: 10.1186/1476-069X-12-22

44. Cheng X, Niu Y, Ding Q, Yin X, Huang G, Peng J, et al. Cadmium exposure and risk of any fracture: A PRISMA-compliant systematic review and meta-analysis. Medicine. (2016) 95:e2932. doi: 10.1097/MD.0000000000 002932

45. Jalili C, Kazemi M, Taheri E, Mohammadi H, Boozari B, Hadi A, et al. Exposure to heavy metals and the risk of osteopenia or osteoporosis: a systematic review and meta-analysis. Osteoporos Int. (2020) 31:1671-82. doi: 10.1007/s00198-020-05429-6

Conflict of Interest: The authors declare that the research was conducted in the absence of any commercial or financial relationships that could be construed as a potential conflict of interest.

Copyright (c) $2021 \mathrm{Li}$, Lin, Zhang, Meng, Hu and Yu. This is an open-access article distributed under the terms of the Creative Commons Attribution License (CC BY). The use, distribution or reproduction in other forums is permitted, provided the original author(s) and the copyright owner(s) are credited and that the original publication in this journal is cited, in accordance with accepted academic practice. No use, distribution or reproduction is permitted which does not comply with these terms. 